\title{
A ATIPICIDADE DOS MEIOS EXECUTIVOS NO CÓDIGO DE PROCESSO CIVIL BRASILEIRO DE 2015
}

\section{ATYPICAL ENFORCEMENT TECHNIQUES ON BRAZILIAN CIVIL PROCEDURE CODE OF 2015}

\author{
Rafael de Oliveira Lima ${ }^{1}$
}

\section{RESUMO}

A efetividade da tutela jurisdicional é tema que sempre preocupou os juristas, tendo sido um dos motores das reformas processuais empreendidas no Brasil e no mundo. A necessidade de franquear um acesso à justiça tange especialmente à atividade jurisdicional executiva, por lidar com a satisfação concreta dos direitos tutelados. A partir de métodos de pesquisa dialético e histórico-comparativo, pretende-se analisar as reformas do CPC/1973 e o atual CPC, sob o enfoque da atipicidade dos meios executivos, enunciada no novel código como instituto de aplicação genérica, independente da natureza da obrigação tutelada e da execução pretendida.

Palavras-chave: Processo. Efetividade. Acesso à justiça. Tutela executiva. Atipicidade dos meios executivos.

\begin{abstract}
The legal protection effectivity has always worried jurists, being one of the biggest causes for procedures changes in Brazil and in the world. The necessity of allowing access to justice concerns especially to enforcement judicial activity, for it deals directly with effective and factual satisfaction of rights. Trough dialetic and historic-comparative method of research, the study intend to analyse CPC/1973 procedures changes and CPC/2015 promulgation, by focus of atypical enforcement techniques, that came written on the new code as an institute of generic application, regardless the nature of obligation to be protected and enforcement procedure appropriate to it.
\end{abstract}

Keywords: Judicial process. Effectivity. Access to justice. Enforcement judicial activity. Atypical enforcement techniques.

\footnotetext{
${ }^{1}$ Advogado e mestrando em Direito Processual pela Universidade Federal do Espírito Santo - UFES, Espirito Santo (Brasil). E-mail: rafael@piantavigna.com.br
} 


\section{INTRODUÇÃO}

A efetividade da tutela jurisdicional não é tema novo, e sem dúvidas constitui fenômeno que há muito tempo preocupa os juristas e operadores do direito no Brasil e no mundo, tendo sido o grande desafio da processualística no século XX franquear aos cidadãos um efetivo acesso à justiça.

Com efeito, o desafio acima destacado assume especial relevância quando entendido o acesso à justiça não como uma garantia formal de bater às portas do Judiciário, mas sim enquanto um acesso efetivo a uma ordem jurídica justa que proporcione uma tutela adequada, efetiva e em tempo razoável.

Nesse sentir, a lição de Mauro Capelletti (1988, p. 8), segundo o qual o acesso à justiça deve representar cumulativamente que o sistema deve ser igualmente acessível a todos e deve produzir resultados que sejam individual e socialmente justos.

Fincadas essas premissas, a tutela jurisdicional efetiva reponta como aquela que não se limita a revelar uma norma jurídica concreta, mas também permite efetivamente que haja sua satisfação no mundo dos fatos, preferencialmente nas “condições mais próximas possíveis daquelas que se teria caso não tivesse ocorrido a crise jurídica que teve de ser debelada no Poder Judiciário" (RODRIGUES, 2015, p. 4).

Por aí já se vê que o problema da efetividade da tutela jurisdicional assombra especialmente a tutela executiva, por esta lidar diretamente com a realização ${ }^{2}$ concreta/material dos direitos diante de crises de cooperação ${ }^{3}$, e, mais especificamente ainda, a tutela específica, haja vista que consiste na obtenção de resultado mais próximo possível

\footnotetext{
${ }^{2}$ Confira-se, a respeito, o magistério de Liebman (2007, p. 189): "La giurisdizione non esaurisce i suoi compiti con la cognizione e col giudizio ne è il risultato. [...] oltre a formulare la regola giuridica concreta che disciplina una determinada situazione, bisgona provvedere ad attuarla, a tradurla in fatti reali, modificando la situazione di fato existente, in modo da farla diventare conforme a quella che dovrebbe essere [...] Questa forma dela tutela giurisdizionale del diritto si compie per mezzo del processo d'esecuzione". E da mesma forma, a lição de Guerra (2003, p. 19).

${ }^{3}$ Vale conferir a distinção feita por Marcelo Abelha Rodrigues (2015, p. 11-12) quanto às crises de cooperação, de certeza jurídica e de situação jurídica: "a crise de certeza constitui um conflito de interesses tipificados pela necessidade de se obter do Poder Judiciário uma certeza jurídica acerca da existência ou inexistência de uma relação jurídica, ou excepcionalmente sobre a autenticidade ou falsidade de um documento. Já a crise de situação jurídica constitui-se em um conflito de interesses tipificado pela necessidade desse obter do Poder Judiciário uma situação jurídica nova, que represente uma mudança jurídica da situação anterior que se encontrava em conflito. Já a crise de cooperação (adimplemento ou descumprimento) configura-se em modalidade de crise tipificada pela necessidade de se alcançar do Poder Judiciário o cumprimento de norma jurídica descumprida".
} 
daquele caso o processo não fosse necessário ${ }^{4}$ o que, via de regra, demanda uma colaboração do devedor, sujeito que se recusou, a todo momento, a cumprir com uma obrigação ou um dever legal e que, costumeiramente, não assume conduta distinta após ser condenado.

O insigne Araken de Assis (2013, p. 105) elucida tal questão com propriedade ao assinalar que a tutela executiva se liga detidamente às situações em que a revelação da norma jurídica concreta não é capaz de por si só de satisfazer no mundo dos fatos o direito, e, para tanto, necessário se faz, via de regra, que o Estado atue coativamente sobre o executado, diferentemente do que se verifica no âmbito das crises de certeza jurídica e de situação jurídica, nas quais os provimentos, respectivamente, declaratório e constitutivo por si só são capazes de implicar eficácia no âmbito do mundo dos fatos.

À evidência, o problema da efetividade toma ainda maior complexidade, historicamente, no campo da tutela específica de obrigações de fazer e não fazer infungíveis, uma vez que, nestes casos, não há como se obter satisfação adequada do direito da forma mais próxima possível ao adimplemento espontâneo senão pela colaboração do vencido.

Nesse contexto se insere, a partir de uma perspectiva ampla, o problema que será aqui analisado: compreender como a questão da efetivação dos direitos foi abordada no Brasil, inclusive com análise em direito comparado, e como se deu o aperfeiçoamento das técnicas processuais atinentes à tutela jurisdicional executiva.

Dentro dessa perspectiva ampla, o tema-objeto específico do estudo será como a previsão da atipicidade dos meios executivos na legislação processual brasileira contribuiu para tal evolução a partir de sua inserção no ordenamento na década de 1990, e como está delineado tal princípio no novo Código de Processo Civil (CPC/2015 - Lei nº 13.105/2015), que recentemente entrou em vigor.

Com efeito, caminhando de encontro à rigidez da legislação processual executiva brasileira original de 1973, marcada por procedimentos executivos específicos e meios executivos típicos a cada tipo de obrigação tutelada (GUERRA, 2003, p. 61-62), estão as reformas processuais pós-Constituição Federal de 1988 (CF/1988), encontrando-se no CPC/2015 mais um momento inovador em busca de reduzir o problema da insuficiência e da ineficiência das técnicas executivas.

\footnotetext{
${ }^{4}$ A respeito do conceito de tutela específica, confira-se Marcelo Abelha Rodrigues (2010, p. 768): "A tutela específica é a obtenção de um resultado que coincida no plano do direito material com aquele que se teria caso não fosse necessário o processo, ou seja, o mesmo resultado obtido caso houvesse o adimplemento espontâneo da obrigação ou dever legal". Em sentido semelhante: BRAGA; CUNHA; DIDIER JUNIOR; OLIVEIRA, 2012, p. 430 .
} 
Isso porque o CPC/2015 tratou de elastecer a abrangência do princípio da atipicidade dos meios executivos, prevendo uma verdadeira generalização das medidas de efetivação atípicas para qualquer tipo de execução (DIDIER JUNIOR; FREIRE; MACEDO; PEIXOTO, 2015, p. 218), não importando a natureza da prestação devida, o que traz implicações necessárias de análise, especialmente em relação às execuções e aos cumprimentos de sentença relativos a pagamento de quantia, os quais, até então, não eram abrangidos pela atipicidade referenciada.

Tal novidade é tão marcante que Fernando da Fonseca Gajardoni (2015, não paginado) enxerga no CPC/2015 uma "Revolução Silenciosa" em relação ao procedimento executivo por quantia, haja vista que passa a ser possível ao magistrado escolher dentre meios coercitivos e sub-rogatórios aquele que se mostrar no caso concreto mais adequado para a realização da função executiva, conquista esta que já era realidade quanto às obrigações de fazer, não fazer e entrega de coisa no Código de Processo Civil de 1973 (CPC/1973), após as reformas de 1994 e 2002.

Portanto, assumindo como premissas métodos de pesquisa dialético e históricocomparativo, propõe-se a análise crítica e reflexiva quanto à nova conformação dos meios executivos (suas potencialidades e seus limites) no CPC/2015, justificando-se o estudo pela necessidade histórica e atual de entendimento do fenômeno da (in)efetividade da tutela jurisdicional, notadamente a executiva, a fim de que se possa compreender quais as técnicas de efetivação dos direitos mais adequadas para a consecução de uma tutela justa, efetiva e em tempo razoável, abordando-se experiências colhidas do direito comparado e dando-se atenção especial ao princípio da atipicidade dos meios executivos.

A partir de uma perspectiva geral, examina-se o fenômeno da ineficiência das técnicas de efetivação dos direitos no ordenamento brasileiro, notadamente a partir das reformas processuais que foram engendradas sob os influxos da $\mathrm{CF} / 1988$, com vistas ao aperfeiçoamento das técnicas processuais atinentes à tutela jurisdicional executiva.

Sob um ponto de vista mais específico, o objetivo é a análise do princípio da atipicidade dos meios executivos e de como ele contribuiu para a busca de uma tutela mais justa e efetiva no âmbito do processo civil brasileiro, desde sua inserção no ordenamento a partir da década de 1990 até suas novas perspectivas no CPC/2015. 


\section{A EFETIVIDADE DA TUTELA JURISDICIONAL E A NOVA ORDEM CONSTITUCIONAL DE 1988: DAS REFORMAS PROCESSUAIS DO CPC/1973 AO NOVO CPC}

A preocupação com a efetividade da tutela jurisdicional, notadamente da tutela executiva, foi, sem sombra de dúvidas, o principal motor das reformas processuais pelas quais passou a legislação processual civil brasileira, a partir dos influxos da nova ordem constitucional de 1988, que, pregando valores aliançados ao paradigma do Estado Democrático Constitucional, trouxe à tona a necessidade de que a atividade jurisdicional assumisse sua capacidade emancipatória e sua vinculação a valores constitucionais, tais como a efetividade do acesso à justiça e a razoabilidade de duração do processo (ZANETI JUNIOR, 2014, p. 42-48 passim).

Não à toa, a partir da década de 1980, diversos juristas passaram a se debruçar sobre o estudo de temas como a efetividade da tutela jurisdicional, o acesso à justiça adequado, tempestivo e efetivo, como se nota nos estudos promovidos no Brasil, dentre outros, por José Carlos Barbosa Moreira (1984, p. 27-42) e Cândido Rangel Dinamarco (1987), este último responsável pela publicação, no ano de 1987, da obra "A instrumentalidade do processo", considerada como a certidão de nascimento da terceira fase metodológica do processo. ${ }^{5}$

Tais preocupações se mostravam novidade à época, tendo em vista que o ordenamento jurídico brasileiro havia sido fortemente influenciado pelos ideais liberais clássicos do século XIX até metade do século XX (e.g. liberdade, propriedade, segurança jurídica, não intervencionismo estatal, intangibilidade da vontade do particular - nemo praecise cogi ad factum).

E o Código de Processo Civil brasileiro de 1973 (CPC/1973) era um grande e nítido exemplo disso, isto é, de como a codificação brasileira sofreu tais influxos liberais, notadamente no que tange à tutela executiva, a qual efetivamente é responsável por interferir na esfera jurídica dos particulares. ${ }^{6}$

\footnotetext{
${ }^{5}$ A terceira fase metodológica processual é identificada, em contraposição às duas fases anteriores (o praxismo e o processualismo científico), como um momento em que o processo é visto como instrumento à serviço da ordem jurídica substancial (direito material) e com objetivo maior de pacificação social (CINTRA; DINAMARCO; GRINOVER, 2006, p. 47). Para melhor compreensão sobre as fases metodológicas do processo, confira-se: MITIDIERO, 2009, p. 23-63; SIQUEIRA, 2008, p. 1-25.

${ }^{6}$ Nesse sentido, colhe-se da lição de Araken de Assis (2013, p. 105) que: "no âmbito da atividade cognitiva, a missão judicial transforma o fato em direito; na execução, o direito, ou seja, a regra jurídica concreta, há de traduzir-se em fatos".
} 
A tipicidade dos meios executivos revelava-se, nesse contexto, um importante mecanismo de controle e de delimitação da atuação e da interferência do Estado-juiz na liberdade e propriedade do particular, garantindo ao executado que "só perderia seus bens em um processo específico, com um mínimo de previsibilidade, e, especialmente, sabendo de antemão quais seriam as armas executivas a serem utilizadas pelo Estado durante a atuação executiva" (RODRIGUES, 2015, p. 20). ${ }^{7}$

Como resultado disso, projetou-se um magistrado pouco participativo/atuante (RODRIGUES, 2015, p. 18-19 passim), haja vista que estava obrigado a seguir estritamente o procedimento executivo previsto no $\mathrm{CPC} / 1973$ e as medidas executivas ali dispostas, sem qualquer margem de liberdade para a escolha daquela que se mostrasse mais adequada à rápida e à efetiva satisfação do direito exequendo (MARINONI, 2004a, p. 42).

As reformas empreendidas no $\mathrm{CPC} / 1973^{8}$ foram responsáveis, justamente, por dar novo corpo à tutela executiva e representaram paulatinamente a superação do princípio da tipicidade dos meios executivos, tal qual se apresentava no modelo original do CPC/1973, bem como no antigo Código de Processo Civil de 1939 (CPC/1939).

Abra-se parêntesis para se dizer que, obviamente, não se está cogitando de superação integral do princípio da tipicidade dos meios executivos, notadamente no que diz respeito à execução/cumprimento de sentença de pagamento de quantia, haja vista que o próprio CPC/2015 mantém a previsão de um itinerário típico que deve ser observado, segundo a mais abalizada doutrina, restando às medidas atípicas caráter de subsidiariedade (RODRIGUES, 2015, p. 40).

Ato contínuo, retornando o foco ao princípio da (a)tipicidade dos meios executivos, cumpre rememorar, de forma breve, como tal princípio foi paulatinamente sofrendo mitigações com as reformas processuais empreendidas no CPC/1973, o que ajuda a demonstrar com mais nitidez a grande inovação trazida com o CPC/2015.

\footnotetext{
${ }^{7}$ Vale conferir, a esse respeito, o escólio do jurista italiano Crisanto Mandrioli (1975, p. 23).

${ }^{8}$ As reformas processuais pós-CF/1988 não se limitaram a abrir espaço para a atipicidade dos meios executivos. Outra alteração de grande repercussão diz respeito ao fim da autonomia formal dos processos de execução de título judicial, permitindo que tais tutelas fossem prestadas em uma fase subsequente à revelação da norma concreta no processo cognitivo, como ensina Marcelo Lima Guerra (2003, p. 32-35).
} 
Como cediço, foi em $1994,{ }^{9}$ com a edição da Lei ${ }^{\circ}$ 8.972/1994, que passou a se prever a atipicidade dos meios executivos no tocante às ações que tivessem por objeto obrigações de fazer e não fazer (art. 461, §5, $\mathrm{CPC} / 1973$ ).

No ano de 2002, por sua vez, foi estendida a aplicação do regime acima referido, abarcando a atipicidade dos meios executivos à tutela das obrigações de entrega de coisa (art. 461-A, §3 $\left.{ }^{\circ}, \mathrm{CPC} / 1973\right)$.

Da visualização deste panorama, fica evidente que, a despeito de esforços teóricos pela aplicação da atipicidade dos meios executivos ao cumprimento de sentença relativo a obrigações de pagar, como se verifica em Luiz Guilherme Marinoni (2004b, não paginado), o CPC/1973 somente conferia textualmente tal tratamento à tutela das obrigações de fazer, não fazer e entrega de coisa (arts 461 e 461-A, do CPC/1973).

Desse modo, o cumprimento de sentença das obrigações de pagar quantia somente podia se valer da incidência da multa do art. 475-J do CPC/1973 e de atos executivos como a penhora de bens e dinheiro, o que permite inferir, desde já, a insuficiência de tais técnicas processuais para lidar com as situações e complexidades que se apresentam cotidianamente no Judiciário (GAJARDONI, 2015, não paginado).

A respeito dos esforços teóricos pela aplicação da atipicidade dos meios executivos ainda sob a vigência do CPC/1973, veja-se o que Guerra (2003, p. 152) salientava já no ano de 2003:

[...] não há nenhuma razão para se dispensar um tratamento privilegiado aos credores de obrigações de fazer ou não fazer, em relação aos demais. Revela-se, assim, anti-isonômico que o credor de obrigações de fazer ou não fazer possa receber tutela executiva de modo mais eficaz, com a utilização de meios executivos adequados à situação concreta e concebidos pelo Juiz caso a caso. Impõe-se, portanto, também em face do princípio constitucional da isonomia (igualmente dotado de status de direito fundamental), a extensão dos poderes reconhecidos ao Juiz no mencionado $\$ 5^{\circ}$ do art. 461 do CPC/1973, a toda e qualquer situação de tutela executiva independentemente da natureza do crédito a ser satisfeito in executivis.

Marinoni (2004b, não paginado), de forma semelhante, já afirmava, uma década atrás, a utilidade de meios executivos atípicos (inclusive, para ele de multa coercitiva), como forma de dissuadir o inadimplemento da sentença condenatória ao pagamento de quantia, tornando desnecessária a execução por expropriação, e reduzindo o custo do processo e a lentidão da satisfação do direito exequendo.

\footnotetext{
${ }^{9}$ Antes disso, em 1990, o princípio da atipicidade já havia conquistado espaço no seio das obrigações de fazer e não fazer relativas às matérias atinentes a direito da criança e do adolescente e a direito do consumidor, no ano de 1990 (respectivamente, Leis nº 8.069/1990 e 8.078/1990).
} 
É dizer, a despeito de tentativas pontuais, está claro que, sob a vigência do CPC/1973, mesmo após as diversas alterações de ordem processual nele realizadas, não era possível visualizar a atipicidade dos meios executivos enquanto um instituto de aplicação genérica (independentemente do tipo de obrigação tutelada e da modalidade de execução pretendida), cabendo analisar, então, até que ponto o CPC/2015 representa roupagem inovadora ao princípio aqui referenciado.

\section{BREVE ESTUDO DE DIREITO COMPARADO: A BUSCA GLOBAL POR UM SISTEMA APTO A CONFERIR RESPOSTAS EFETIVAS E JUSTAS ÀS SITUAÇÕES CARENTES DE TUTELA}

Antes de prosseguir à análise propriamente dita do princípio da atipicidade dos meios executivos no CPC/2015, é inevitável notar, a partir do que foi dito até agora, a semelhança e os influxos, sob a perspectiva de direito comparado, das reformas pós-CF/1988 (incluindo-se aí o CPC/2015 como mais um estágio das transformações pós-CF/1988, isto é, inseridas no contexto do Estado Democrático Constitucional de Direito) com as adaptações por quais passaram ao longo da história sistemas como o francês e o estadunidense, todos com um mesmo objetivo: fazer frente ao fenômeno da inefetividade da tutela dos direitos.

O fenômeno da ineficiência da execução, repita-se, não é regional ou nacional, mas sim mundial, verdadeiramente globalizado, sendo possível, nos últimos anos, visualizar que vários ordenamentos processuais foram reformados para que se modificasse o sistema da execução civil, como é o caso da Espanha em 2000, da Rússia em 2002, de Portugal em 2003, da Itália em 2005, de Honduras em 2007, entre muitos outros (ALVIM; ALVIM; BRUSCHI; CHECHI; COUTO, 2014, p. 15).

Destaque especial, contudo, deve ser dado às adaptações pelas quais passaram o sistema francês e o sistema estadunidense, haja vista que, sem ignorar sistemas como o germânico, ${ }^{10}$ tais sistemas se aproximam do CPC/2015 (no contexto brasileiro), mutatis

\footnotetext{
${ }^{10}$ A respeito da rigidez do sistema germânico, Michele Taruffo (1990, p. 82): "trata-se de um sistema que atribui uma tutela executiva forte para as situações jurídicas que apresentam características definidas a priori pela lei; esta tutela é, porém, rigorosamente tipificada (donde a impossibilidade de adotar-se o remédio 'conforme o caso concreto'), e opera nas situações tipificadas pela lei, donde, também, a dificuldade de estendê-la a situações novas ou que de alguma forma não sejam encartáveis claramente em uma ou outra categoria.”. Confira-se também Araken de Assis (2013, p. 154), no que toca aos instrumentos alemães de indução compulsória do executado, a saber: pagamento de soma de dinheiro (Zwangsgeld/Ordnungsgeld) e ameaça de prisão (Zwangsshaft/Ordnungshaft).
} 
mutandi, enquanto tentativa de se conceber um sistema mais capaz de propiciar uma resposta completa e efetiva às diversas situações carentes de tutela que com o tempo surgiram e continuarão a surgir.

Nesse contexto, destaca-se, na França, a figura da astreinte, que, conquanto tenha sido criada (por intensos esforços jurisprudenciais) especificamente para a tutela de obrigações de fazer e de não fazer, tornou-se instrumento compulsório de alcance geral com grau elevado de cumprimento específico de obrigações de qualquer natureza.

O ensinamento de Michele Taruffo (1990, p. 85-86) é preciso, no que toca à conquista do sistema francês:

\begin{abstract}
O sistema francês [...] acaba por fornecer uma resposta global e polivalente à necessidade de efetividade que se manifesta no terreno da atuação dos direitos [...] utilizando um só instrumento, que, de acordo com os casos concretos, pode ser empregado exclusivamente ou cumulativamente com outros possíveis remédios executivos. Trata-se, contudo, de um instrumento que, se de um lado é muito eficaz, porque o Juiz pode adaptar a força compulsória das astreintes às necessidades de um caso concreto [...], de outro lado, pode ser empregado para tutelar todas as situações jurídicas que encontram o seu reconhecimento num pronunciamento do Juiz. Estáse, pois, diante de uma resposta completa, porque não há situações em relação às quais a ordem do Juiz, independentemente do seu específico conteúdo, não possa ser cumprida através de uma astreinte.
\end{abstract}

No caso da experiência dos Estados Unidos, a ineficiência dos meios executivos ordinários de tutela at law (meios tradicionais, ordinários, voltados à tutela de situações dotadas de conteúdo tipicamente econômico) levou à criação de um sistema paralelo e complementar de tutela denominado Equity, o qual servia à proteção dos novos direitos que emergiam e não eram abrangidos pelas medidas ordinárias (at law), utilizando-se, para tanto, da injunction e do contempt of court.

A injunction consiste na ordem para fazer (mandatory) ou não fazer, ou de cessar um comportamento lesivo (prohibitory), de natureza cautelar ou definitiva, e cuja relevante característica é a sua adaptação, no seu conteúdo específico, a uma situação qualquer carente de tutela (TARUFFO, 1990, p. 74).

Em outras palavras, a injunction ${ }^{11}$ possui o efeito típico de impor uma specific performance (um fazer, não-fazer ou cessar), atuando em conjunto com o contempt of court, o

\footnotetext{
${ }^{11}$ A respeito do instituto da injunction, Geoffrey C. Hazard (HAZARD; TARUFFO, 1993): "an injunction is a judgment that orders the defendant to perform a specified act or to refrain from doing so. An injunction requiring an act is called a mandatory injunction; one requirind that an act not to be done is called a prohibitory injunction".
} 
qual desponta como medida coercitiva vocacionada a gerar o cumprimento dos injunctive decrees (TARUFFO, 1990, p. 73-78 passim). ${ }^{12}$

Visualizadas tais experiências, não há como negar que as reformas processuais engendradas no CPC/1973 sofreram os influxos dos mecanismos acima referenciados e a eles, de certa forma, assemelham-se. ${ }^{13}$

Isso porque, assim como tais figuras representaram grande passo nos seus respectivos sistemas, o CPC/2015, mutatis mutandis, representa mais um passo dado pelo ordenamento brasileiro dentro do contexto de reformas que se iniciou na década de 1990 (pós$\mathrm{CF} / 1988$ ), e tem a potencialidade de representar mais um passo em direção a um sistema apto a propiciar uma resposta completa às situações carentes de tutela, independentemente do seu específico conteúdo, permitindo-se um efetivo e indiscriminado acesso à justiça (TARUFFO, 1990, p. 73).

Em outras palavras, a grande inovação do CPC/2015, conforme será abordado de forma mais específica e estendida no tópico que se segue, está em compreender que o operador do direito tem em suas mãos um manejo mais fluido dos meios executivos (técnicas de efetivação), permitindo-se em demandas voltadas à satisfação de direitos relacionados a deveres de fazer, não fazer, entregar coisa e, inclusive, de dinheiro (pagamento de quantia), a utilização de medidas diversas, desde que condizentes à efetivação tempestiva e adequada de direitos carentes de tutela.

\section{O PRINCÍPIO DA ATIPICIDADE DOS MEIOS EXECUTIVOS NO NOVO CPC: A EFETIVIDADE DO PROCESSO E OS LIMITES AOS PODERES DO JUIZ}

\footnotetext{
${ }^{12}$ No que tange à importância de imposição da medida coercitiva (contempt) aos injunctives decrees, a lição de John F. Dobbyn (1974, p. 216): "the only practical force available to the court for enforcement of its decrees is its ability impose contempt sanctions on the respondent".

${ }^{13}$ Aliás, figuras semelhantes ao contempt of court e à astreinte estão presentes no ordenamento brasileiro desde as reformas empreendidas no Código de Processo Civil brasileiro de 1973: o contempt of court na figura da multa prevista no parágrafo único do art. 14 do CPC/1973; e a astreinte francesa, enquanto medida coercitiva,

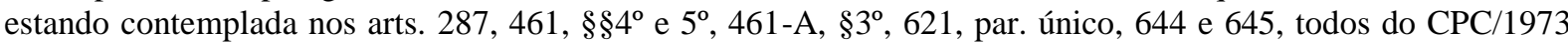
(ASSIS, 2013, p. 154). Cabe destacar que a lição de Araken de Assis merece atualização, em virtude da promulgação do novo Código de Processo Civil, que passa a prever o contempt of court no art. 77, caput, incisos e parágrafos; e a astreinte, nos arts. 536, 537 e 538, cabendo destacar, contudo, que as astreintes são cabíveis hoje não mais apenas em virtude de tais dispositivos, que são relativos a tutela de obrigações específicas, mas em virtude de uma cláusula geral de efetivação contida justamente no art. 139, IV, CPC/2015, tema este que é o objeto deste estudo.
} 
Sob a ótica do Novo CPC, o princípio da atipicidade dos meios executivos encontrase positivado de forma genérica, na Parte Geral do código, questão que, por si só, demanda análise, uma vez que a previsão da atipicidade dos meios executivos não está mais, como ocorria no CPC/1973 (pós-reformas), tão somente em dispositivos detida e especificamente

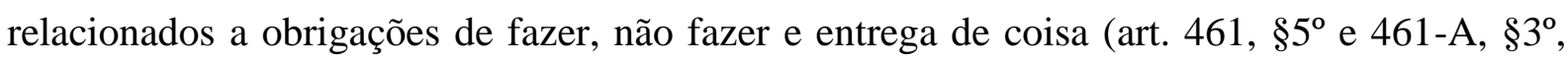
ambos do CPC/1973).

Com o CPC/2015, a previsão da atipicidade dos meios executivos, além de estar contida nos artigos 536, $\S 1^{\circ}$ e $538, \S 3^{\circ}$, ambos do $\mathrm{CPC} / 2015$ (e relativos às obrigações de fazer/não fazer e entrega de coisa, respectivamente), vem escalada também no Capítulo I (Dos poderes, dos deveres e das responsabilidades do Juiz) do Título IV (Do Juiz e dos auxiliares da justiça) do Livro III (Dos sujeitos do processo).

Sem dúvidas, a análise topográfica do CPC/2015 ajuda a demonstrar o tamanho da inovação trazida no que toca aos poderes (poderes-deveres) de o Juiz tomar as medidas mais adequadas à satisfação do direito exequendo, independentemente da natureza da obrigação ou do dever legal carente de tutela.

Fincada essa premissa, fica mais fácil compreender como o princípio da atipicidade dos meios executivos no CPC/2015 assume a feição de poder-dever geral conferido ao magistrado de determinar, independentemente da natureza da situação carente de tutela, todas as medidas coercitivas, sub-rogatórias, mandamentais e indutivas ${ }^{14-15}$ que entender necessárias para a tutela justa, efetiva e em tempo razoável, inclusive para as execuções e cumprimento de sentença de pagamento de quantia (art. 139, IV, do CPC/2015), a despeito da pretensa e aparente incoerência entre direito material a ser tutelado e técnica processual a ser escolhida (RODRIGUES, 2015, p. 61).

Destaque-se, novamente, neste ponto, que não se está dizendo que o CPC/2015 representa o esfacelamento completo da sistemática do CPC/1973 pós-reformas processuais, haja vista que, de um lado, "não há como deixar de perceber, hoje, que entre o processo e o direito material há uma relação de integração [...] o processo deve ser estruturado de acordo com as necessidades do direito material" (MARINONI, 2004a, p. 28); e de outro lado, o próprio CPC/2015 mantém a previsão de um itinerário típico que deve ser observado na

\footnotetext{
${ }^{14}$ Pertinente, aqui, a distinção entre execução direta (sub-rogação) e indireta (coerção) fornecida por Araken de Assis (2013, p. 152-160) e por Marcelo Abelha Rodrigues (2010, p. 728), valendo destacar, ainda, que, na esteira de Marcelo Lima Guerra (2003, p. 40), tanto os meios coercitivos como os sub-rogatórios tratam-se de meios executivos.

${ }^{15}$ Para melhor entendimento do que se tratam e quais as diferenças entre medidas indutivas, mandamentais, coercitivas e sub-rogatórias, confira-se: MEIRELES, 2015, p. 231-246.
} 
execução/cumprimento de sentença de pagamento de quantia, segundo a mais abalizada doutrina, restando às medidas atípicas caráter de subsidiariedade, conforme, aliás, concluiu o Fórum Permanente de Processualistas Civis (FPPC) dando origem ao Enunciado $\mathrm{n}^{\mathrm{o}} 12 .{ }^{16}$

A despeito disso, não há dúvidas de que o CPC/2015 conferiu nítido e indiscutível elastecimento ao princípio da atipicidade dos meios executivos de tal forma a permitir ampla e genericamente (não ilimitada, obviamente) que o magistrado eleja os meios executivos mais adequados à satisfação do direito exequendo e até os cumule.

Esta é a expressa dicção do art. 139, IV, do CPC/2015:

Art. 139. O juiz dirigirá o processo conforme as disposições deste Código, incumbindo-lhe: [...] IV - determinar todas as medidas indutivas, coercitivas, mandamentais ou sub-rogatórias necessárias para assegurar o cumprimento de ordem judicial, inclusive nas ações que tenham por objeto prestação pecuniária; [...] (grifo nosso)

Portanto, o CPC/2015 inegavelmente abre margem para que se alcance uma tutela mais efetiva, inclusive no que toca às obrigações de pagar, haja vista que permite dar solução a situações para as quais o procedimento típico (que, até então, representava o único caminho no CPC/1973) não se mostrava suficiente. ${ }^{17}$

Uma premissa primeira merece, portanto, ser fixada: o art. 139, IV, CPC/2015 aumenta o espectro de poderes do Juiz, por prever uma cláusula geral de efetivação para todas as obrigações, inclusive as pecuniárias de pagar quantia.

Contudo, questão diretamente ligada a esta premissa exsurge e parece preocupar alguns juristas: até que ponto a generalização concedida ao magistrado pode ir? A partir de que fronteira se estaria ultrapassando os limites constitucionais?

A preocupação referenciada pode ser muito bem colhida em Lênio Luiz Streck e Dierle Nunes (2016, não paginado), que entendem que "a melhor interpretação do preceito normativo não é a de buscar um juízo criativo ilimitado e despreocupado com as restrições normativo-constitucionais com fins utilitaristas" e acrescenta que não seria possível com base

\footnotetext{
${ }^{16}$ Diz o Enunciado no 12 do FPPC que: A aplicação das medidas atípicas sub-rogatórias e coercitivas é cabível em qualquer obrigação no cumprimento de sentença ou execução de título executivo extrajudicial. Essas medidas, contudo, serão aplicadas de forma subsidiária às medidas tipificadas, com observação do contraditório, ainda que diferido, e por meio de decisão à luz do art. 499, § 1., I e II (486 [atual art. 489]).

${ }^{17}$ Em outra perspectiva, a generalização pretendida no CPC/2015 assume especial importância na medida em que, historicamente, se demonstrou ser tarefa impossível ao legislador prever/preordenar todos os meios executivos adequados ao atendimento das particularidades de todos os direitos merecedores de tutela.
} 
no artigo 139, IV do CPC/2015 "restringir unilateralmente, a partir da visão utilitarista do magistrado, direitos individuais para obter a satisfação de obrigações pecuniárias".

Com efeito, a preocupação dos Autores não pode nem deve ser desconsiderada, se mostrando precisa quanto à impossibilidade de o art. 139, IV do CPC/2015 se revelar como carta branca para o arbítrio; cabe-nos destacar, contudo, que entendemos, com a devida vênia, que determinadas restrições individuais podem representar a pedra de toque entre a obtenção de uma tutela satisfativa/efetiva/eficiente/tempestiva e a frustração (muito comum, para não se dizer a regra) das pretensões carentes de tutela (o famoso "ganhou, mas não levou", nas palavras dos próprios Lênio Streck e Dierle Nunes).

Imaginemos a seguinte situação: um devedor de determinada quantia certa, muito embora ausente de bens sujeitos à expropriação ao que consta dos autos, é visto rotineiramente na área de embarque internacional do aeroporto do estado em que possui domicílio.

A imposição de multa coercitiva nesses casos surtirá qualquer efeito positivo em relação à obtenção de uma tutela efetiva, adequada e eficiente? Certamente que (e via de regra será assim) não! Até porque, como cogitado no exemplo acima destacado, não foram encontrados bens sujeitos à expropriação no patrimônio do devedor e nenhum valor ainda foi pago pelo devedor inadimplente.

O que fazer? Seria o caso de se contentar com o "ganhou, mas não levou", que a cada dia faz a Justiça menos valorizada e credibilizada perante a sociedade?

Não entendemos ser o caso, com toda a vênia a quem pense diferente.

Já há muito se diz que a atividade jurisdicional não serve tão somente para declaração da vontade concreta da lei (como ensinava Chiovenda em suas "Instituições de Direito Processual Civil”) ${ }^{18}$ ou para a obtenção de mera revelação de norma jurídica concreta; sendo cediço que a efetiva, tempestiva e adequada tutela dos direitos é hoje a finalidade do processo, de acordo com as raias do Estado Constitucional Democrático de Direito (MITIDIERO, 2015, p. 50).

Desse modo e partindo de tal premissa (de que estamos no seio de um Estado Constitucional Democrático de Direito), o emprego e o manejo do art. 139, IV, CPC/2015 certamente abre margem, na hipótese acima cogitada, para que o devedor seja intimado ao

\footnotetext{
${ }^{18}$ Nas palavras de Giuseppe Chiovenda (2002, p. 59): “a função pública desenvolvida no processo consiste na atuação da vontade concreta da lei, relativamente ao bem da vida que o autor pretender garantido por ela. Objetivo dos órgãos jurisdicionais é afirmar e atuar aquela vontade da lei que eles estimam existente como vontade concreta, à vista dos fatos que consideram como existente".
} 
pagamento do débito exequendo, sob pena de imposição de medida coercitiva consubstanciada, por exemplo, em apreensão de seu passaporte.

Tal tipo de medida, que pode ser imaginado em uma série de outras situações, definitivamente se mostra mais adequado aos nortes de efetividade e de eficiência propostos pelo novel diploma processual e também pelos vetores de boa-fé objetiva e cooperação (arts. $4^{\mathrm{o}}, 5^{\mathrm{o}}$ e $\left.6^{\mathrm{o}}, \mathrm{CPC} / 2015\right) .{ }^{19}$

Ainda que a medida não atue na obtenção da tutela propriamente dita, aquela serve para invocar o devedor ao processo, nem que seja para se manifestar dizendo que viaja pelo motivo ' $\mathrm{x}$ ', e, portanto, não pode ter esse direito restringido, ou mesmo para informar que o dinheiro com que compra a passagem não é dele.

O que não se pode mais admitir é aquilo que se vive todos os dias na prática forense: devedores que se esquivam do cumprimento de suas obrigações, utilizando-se ou não de terceiros (as famosas fraudes do credor e fraudes à execução), aproveitando-se das insuficiências dos procedimentos típicos de execução, especialmente de expropriação.

As considerações aqui lançadas não passaram desapercebidas de Fernando da Fonseca Gajardoni (2015, não paginado), que aventou uma série de situações em que o manejo da atipicidade pode ser fatal para que se obtenha a tão esperada tutela efetiva, adequada e tempestiva dos direitos, confira-se: (i) não efetuado o pagamento de dívida oriunda de multas de trânsito, e superados os expedientes tradicionais de adimplemento (penhora de dinheiro e bens), seria lícito o estabelecimento da medida coercitiva/indutiva de suspensão do direito a conduzir veículo automotor até o pagamento do débito (inclusive com apreensão da $\mathrm{CNH}$ do devedor); (ii) não efetuado o pagamento de verbas salariais devidas a funcionários da empresa, possível o estabelecimento de vedação à contratação de novos funcionários até que seja saldada a dívida; (iii) não efetuado o pagamento de financiamento bancário na forma e no prazo avençados, possível, até que se tenha quitação, que se obstem novos financiamentos, ou mesmo a participação do devedor em licitações, etc.

Veja-se, e é preciso que isso fique claro, que de forma alguma se está afirmando que medidas como a apreensão do passaporte (ou mesmo de $\mathrm{CNH}$, em outro exemplo) devem ser manejadas e empregadas a título de punição daquele devedor que não colabora com o

\footnotetext{
${ }^{19}$ Art. 4o As partes têm o direito de obter em prazo razoável a solução integral do mérito, incluída a atividade satisfativa.

Art. 5o Aquele que de qualquer forma participa do processo deve comportar-se de acordo com a boa-fé.

Art. $6^{\mathrm{o}}$ Todos os sujeitos do processo devem cooperar entre si para que se obtenha, em tempo razoável, decisão de mérito justa e efetiva.
} 
cumprimento dos comandos jurisdicionais; isto é, não estamos abrindo margem em nosso discurso para que medidas de tal estirpe sejam utilizadas para punição do devedor que atenta contra a dignidade da justiça. ${ }^{20}$

Para tal tipo de conduta, tem-se, como cediço, a aplicação de multas por litigância de má-fé e ato atentatório à dignidade da justiça, conforme arts. $77, \S 2^{\circ}$ e 774 , par. único, ambos do $\mathrm{CPC} / 2015$.

Não se pode entender, portanto, que a generalização das medidas atípicas se confunde com a inexistência de mecanismos de controle de aplicação do instituto, e tampouco se pode pensar que a previsão legal do CPC/2015 quanto à atipicidade resolveu todos os problemas de efetividade da tutela executiva no processo civil brasileiro.

Obviamente é indiscutível que as medidas atípicas não podem ser aplicadas de forma indiscriminada, para que não haja abuso por parte do magistrado e prejuízo a direitos fundamentais daquele que figura como sujeito atingido pelas referidas medidas, o que colocaria em descrédito a própria legitimidade e credibilidade do Poder Judiciário.

Sendo assim, em primeiro lugar, o manejo do princípio da atipicidade dos meios executivos no que toca às obrigações de pagar quantia, como aponta Marcelo Abelha Rodrigues (2015, p. 40 e 63), depende do esgotamento das medidas típicas e da observância do devido processo legal (art, 5, LIV e LV, CF/1988; art. 10, CPC/2015).

É expressa e textual nesse sentido a conclusão a que chegou o Fórum Permanente de Processualistas Civis (FPPC), entendimento que foi encartado no Enunciado de ${ }^{\circ} 12$ :

\footnotetext{
A aplicação das medidas atípicas sub-rogatórias e coercitivas é cabível em qualquer obrigação no cumprimento de sentença ou execução de título executivo extrajudicial. Essas medidas, contudo, serão aplicadas de forma subsidiária às medidas tipificadas, com observação do contraditório, ainda que diferido, e por meio de decisão à luz do art. 499, § 1. ${ }^{\circ}$, I e II.
}

\footnotetext{
${ }^{20}$ Este nos parece, aliás, o equívoco cometido em recente decisão proferida por magistrada da 2a Vara Cível do Foro Regional de Pinheiros em execução de título extrajudicial registrada sob no 4001386-13.2013.8.26.0011, que determinou a suspensão da Carteira Nacional de Habilitação e a apreensão do Passaporte de devedor sem enquadrar e demonstrar que tais medidas de fato poderiam representar coerção do réu, compelindo-o ao pagamento. Faltou à magistrada responder em sua decisão o porquê do emprego especificamente da apreensão da $\mathrm{CNH}$ e do passaporte: por acaso, o devedor era visto rotineiramente dirigindo veículos automotores? $\mathrm{Ou}$, ainda, era viajante habitual, fazendo-se presença constante nos aeroportos do país e do exterior? Veja-se que, com isso, a decisão incorre em outra deficiência, consistente na ausência de fundamentação adequada (art. 489, §1으, do CPC/2015) por não enunciar as circunstâncias do caso concreto que autorizavam e sugeriam a efetividade das medidas impostas. Diante disso, parece-nos que a decisão mais parece aplicar as medidas atípicas como forma de punição do que como meio voltado à coerção do devedor e, portanto, ao adimplemento do dever, o que não é possível, haja vista a existência de disciplina própria para as punições processuais por ato de litigância de má-fé ou atentatório à dignidade da justiça.
} 
Além disso, lançar mão das medidas atípicas como as mencionadas acima (apreensão de passaporte, suspensão do direito de dirigir, etc) necessita de que se constate que tais medidas de algum modo podem de fato contribuir para a obtenção da tutela pretendida de forma efetiva, tempestiva e adequada, sob pena de se submeter, sem qualquer utilidade, o executado a situação que fira o princípio da menor onerosidade possível (previsto no art. 805). $21-22$

É dizer, em outras palavras, que, apenas se assumirem função de coerção do réu ao adimplemento, tais medidas coercitivas poderão ser empregadas, porque como se infere da leitura atenta do art. 139, IV, do CPC/2015, a previsão de atipicidade dos meios somente e tão somente se presta a "assegurar o cumprimento de ordem judicial".

A liberdade concedida ao Juiz certamente lhe impõe, de outro lado, a necessidade de que não a utilize para contrariar a lei ou mesmo princípios do Direito, conforme se verificaria na hipótese de ser determinada prisão civil do devedor (não sendo o caso obviamente de dívida alimentar).

Portanto, entendemos que, via de regra, além do já mencionado esgotamento do itinerário típico e das medidas típicas (tema que foi inclusive objeto de Enunciado pelo FPPC), para que se possa manejar as medidas atípicas, é indispensável que haja indícios de que o devedor está se esquivando do pagamento da dívida, muito embora pudesse adimpli-la.

Nesse sentido, tomando por referência o exemplo do devedor que viaja constantemente, mas que não paga suas dívidas, imagine-se como seria inútil à efetividade da tutela jurisdicional a apreensão do passaporte se aquele devedor que é visto rotineiramente na área de embarque internacional do aeroporto de seu estado viaja apenas porque presta serviço voluntário em comunidades carentes de países da América Latina, sendo que as passagens são compradas diretamente pela ONG a que o devedor é associado.

Nesse mesmo sentido, a lição de Daniel Amorim Assumpção Neves e Flávio Tartuce (2016, p. 628), para os quais o juiz deve atuar com razoabilidade no emprego das medidas atípicas:

\footnotetext{
${ }^{21}$ Art. 805. Quando por vários meios o exequente puder promover a execução, o juiz mandará que se faça pelo modo menos gravoso para o executado.

Parágrafo único. Ao executado que alegar ser a medida executiva mais gravosa incumbe indicar outros meios mais eficazes e menos onerosos, sob pena de manutenção dos atos executivos já determinados.

${ }^{22} \mathrm{O}$ menor sacrifício possível, também chamado menor onerosidade possível, é princípio atinente à execução civil e decorre da necessidade de moderação dos meios processuais a empregar na execução, visando à proteção do devedor contra excessos executivos, com vistas a que uma satisfação que poderia ter sido alcançada por meios menos onerosos seja obtida por meios mais agressivos á esfera do executado.
} 
[...] deve o juiz atuar com imparcialidade e razoabilidade. Não pode, por exemplo, determinar a suspensão da habilitação de devedor que tem a condução de automóveis sua fonte de subsistência (taxista, motorista do UBER, motorista de ônibus). Tampouco parece correto proibir a contratação de novos funcionários de empresa que deve verbas salariais quando a contratação for indispensável ao próprio funcionamento da empresa.

É preciso que fique claro que a atipicidade de forma alguma pode representar ofensa a direitos e a garantias constitucionais, ao invés de protegê-los. A previsão de medidas atípicas só existe e só pode ser cogitada quando assuma alguma utilidade real à obtenção da tutela efetiva, adequada e tempestiva.

No escólio de Luiz Guilherme Marinoni, Sergio Arenhart e Daniel Mitidiero (2015, p. 846), os meios de execução empregados têm que se revelarem capazes de proporcionar faticamente a tutela e ao mesmo tempo serem idôneos à sua prestação, causando a menor restrição possível à esfera jurídica do réu.

Em outras palavras, as medidas atípicas adotadas devem ser adequadas e necessárias, isto é, com aptidão para a promoção do fim da tutela do direito e ao mesmo tempo com a menor possível extensão de restrição à esfera do réu (MARINONI; ARENHART; MITIDIERO, 2015, p. 846), sendo óbvio que a aferição do binômio adequação/necessariedade dependerá diretamente das circunstâncias e peculiaridades do caso concreto.

A análise das circunstâncias do casos, ressalte-se, é importantíssima, bastando que se comparem alguns exemplos: a) réu-devedor não possui bens penhoráveis e encontra-se "completamente" insolvente; b) réu-devedor não possui bens penhoráveis, mas é visto rotineiramente viajando para o exterior (com dinheiro sabe-se lá de quem...).

Evidentemente, no primeiro exemplo, a apreensão de passaporte do réu não representará nenhum poder de coerção sobre este, uma vez que, por ser insolvente, viajar para fora do Brasil está fora de seu alcance. Diferente situação se tem no exemplo "b", uma vez que a ameaça de apreensão do passaporte do réu em caso de não pagamento do débito exequendo, poderá sim assumir função coercitiva.

Situação semelhante pode-se visualizar quanto à apreensão da $\mathrm{CNH}$ : um réu-devedor que, embora não possua carro, é visto constantemente dirigindo veículos importados, poderá sentir-se verdadeiramente compelido ao adimplemento se lhe for imposta medida coercitiva de apreensão de $\mathrm{CNH}$ em caso de não cumprimento do comando jurisdicional.

Da mesma forma, um devedor conhecido por ser fanático por futebol e estar presente em todos os jogos de seu clube pode se sentir pressionado psicologicamente caso a medida 
executiva empregada pelo Judiciário seja a proibição de frequentar estádios de futebol, cabendo frisar apenas que deve haver ao menos fortes indícios nos autos de que tal devedor oculta patrimônio.

Fica evidente, portanto, que a análise percuciente do caso concreto é crucial para a imposição de medida atípica, como as coercitivas acima destacadas.

Além disso, é indispensável que a decisão que imponha a medida atípica venha motivada e fundamentada, com estrita observância ao disposto no art. 489, §1 ${ }^{\circ}$, do CPC/2015, inclusive demonstrando quais circunstâncias do caso sugerem a adequação, efetividade e eficiência da medida imposta.

O que se quer dizer, enfim, é que a restrição de direitos do devedor (apreensão de passaporte, suspensão de $\mathrm{CNH}$, impedimento de participar de licitação, etc) apenas será adequada se representar efetivamente técnica capaz de se obter uma tutela satisfativa e justa, não sendo admissível que se utilize de tais técnicas atípicas de execução indireta de forma indiscriminada, como se o devedor/executado também não fosse sujeito de direitos.

\section{CONCLUSÃO}

A previsão de dispositivo que encarta a generalização de medidas atípicas representa grande passo (mais um degrau que se sobe desde a Constituição da República de 1988) rumo a um sistema mais apto a atender de forma efetiva e adequada os mais variados direitos carentes de tutela, independentemente da natureza da obrigação (fazer, não fazer, entrega de coisa ou pagamento de quantia). Disso não há dúvidas!

Uma dificuldade, contudo, demanda atenção: como a atipicidade será manejada pelo Poder Judiciário e também, diga-se de passagem, pelos advogados, que são os que requererão a aplicação das medidas atípicas.

Isso porque, nunca é demais lembrar, alterações legislativas, como a promulgação do CPC/2015, não são capazes, por si só, de resolverem todos os problemas do direito brasileiro, sendo imprescindível o compromisso dos juristas, dos operadores de direito e do Judiciário para que o novel diploma concretize efetivamente a conquista que representa na tentativa de solução dos problemas históricos (e também atuais) de inefetividade da tutela jurisdicional executiva. 
Em outras palavras, o sucesso de qualquer sistema jurídico depende não apenas de boas normas, mas, sobretudo, da existência de uma cultura jurídica apropriada a orientar aqueles incumbidos de operá-lo, como salienta Guerra (2003, p. 11).

Daí a importância de se firmar não só o entendimento acerca da potencialidade da utilização dos meios atípicos de execução, mas também de se destacar uma perspectiva de controle e limites do manejo de tais meios, porquanto de modo algum podem se prestar a ofensa e lesão a direitos fundamentais.

A atipicidade dos meios executivos existe, ao contrário, para a tutela de direitos de forma efetiva, adequada e tempestiva e só deve ser invocada, diante disso, quando os meios típicos não se mostrarem suficientes e quando, de fato, houver ao menos indícios de que o devedor poderá vir a pagar caso seja sujeito aos efeitos de atos executivos atípicos, sob pena de sujeitar o executado a onerosidade que em nada contribui à tutela jurisdicional, e, a bem da verdade, apenas fere o princípio do menor sacrifício possível e os direitos fundamentais do executado.

Indispensável, portanto, que: (i) as medidas coercitivas atípicas sejam lançadas apenas caso o itinerário típico se mostre frustrado; (ii) as circunstâncias e peculiaridades do caso concreto indiquem a possibilidade de uso das medidas, pois são vocacionadas à efetividade da tutela - sob pena de se implicar onerosidade excessiva e inútil ao executado; e (iii) o magistrado fundamente de forma devida, com observância ao art. 489, §1 ${ }^{\circ}, \mathrm{CPC} / 2015$, o porquê da aplicação da medida atípica pinçada por ele.

O manejo indiscriminado do art. 139, IV, do CPC/2015 seria temerário, devendo-se seguir as trilhas lançadas neste estudo para que a utilização de medidas atípicas não acabe trazendo o resultado inverso daquele que o legislador certamente propôs para o novel diploma processual civil.

\section{REFERÊNCIAS}

ALVIM, Arruda; ALVIM, Eduardo Arruda; BRUSCHI, Gilberto Gomes; CHECHI, Mara Larsen; COUTO, Mônica Bonetti (Coords.). Execução civil e temas afins do CPC/1973 ao Novo CPC: 
estudos em homenagem ao professor Araken de Assis. $1^{\text {a }}$ ed. São Paulo: Revista dos Tribunais, 2014.

ASSIS, Araken de. Manual da execução. 16 ed. rev. e atual. São Paulo: Revista dos Tribunais, 2013.

BARBOSA MOREIRA, José Carlos. Temas de direito processual. São Paulo: Saraiva, 1984.

BEDAQUE, José Roberto dos Santos. Efetividade do processo e técnica processual. São Paulo: Malheiros, 2006.

BRAGA, Paula Sarno; CUNHA, Leonardo José Carneiro da; DIDIER JUNIOR, Fredie; OLIVEIRA, Rafael. Curso de Direito Processual Civil. v. 5. 4ª ed. Bahia: JusPODIVM, 2012.

CAPELLETTI, Mauro. Acesso à Justiça. Tradução de Ellen Gracie Northfleet. Porto Alegre: Fabris, 1988.

CINTRA, Antonio Carlos de Araújo; DINAMARCO, Cândido Rangel; GRINOVER, Ada Pellegrini. Teoria Geral do Processo. 22a ed. São Paulo: Malheiros, 2006.

CHIOVENDA, Giuseppe. Instituições de Direito Processual Civil. V. I. Campinas: Bookseller, 2002.

DINAMARCO, Cândido Rangel. A instrumentalidade do processo. São Paulo: Revista dos Tribunais, 1987.

DOBBYN, John F. Injunctions. Saint Paul: West Publishing, 1974.

DIDIER JUNIOR, Fredie; FREIRE, Alexandre; MACEDO, Lucas Buril de; PEIXOTO, Ravi Medeiros (coord.). Coleção Novo CPC - Doutrina selecionada. v. 5. Bahia: JusPODIVM, 2015.

GAJARDONI, Fernando da Fonseca. A revolução silenciosa da execução por quantia. 2015. Disponível em: 〈http://jota.info/a-revolucao-silenciosa-da-execucao-por-quantia〉. Acesso em: 07 jun. 2016. 
GUERRA, Marcelo Lima. Direitos fundamentais e a proteção do credor na execução civil. São Paulo: Revista dos Tribunais, 2003.

Execução Indireta. São Paulo: Revista dos Tribunais, 1998.

LIEBMAN, Enrico Tullio. Manuale de Diritto Processuale Civile. $7^{\mathrm{a}}$ ed. Milano: Giuffrè, 2007.

MARINONI, Luis Guilherme. Técnica processual e tutela dos direitos. São Paulo: Revista dos Tribunais, 2004a.

A efetividade da multa na execução da sentença que condena a pagar dinheiro.

2004b. Disponível em: <http://www.egov.ufsc.br/portal/sites/default/files/anexos/17910-17911-1PB.htm>. Acesso em: 12 mar. 2016.

MARINONI, Luiz Guilherme; ARENHART, Sergio; MITIDIERO, Daniel. Novo Curso de Processo Civil. V. 2. São Paulo: Revista dos Tribunais, 2015.

MEIRELES, Edilton. Medidas sub-rogatórias, coercitivas, mandamentais e indutivas no Código de Processo Civil de 2015. Revista de Processo, vol. 247/2015, p. 231-246.

MITIDIERO, Daniel. A colaboração no processo civil. São Paulo: Revista dos Tribunais, 2015.

NEVES, Daniel Amorim Assumpção; TARTUCE, Flávio. Manual de Direito do Consumidor. $5^{a}$ ed. Rio de Janeiro: Forense, 2016.

NUNES, Dierle; STRECK, Lênio Luiz. Como interpretar o art. 139, IV, do CPC? Carta branca para o arbítrio? 2016. Disponível em: < http://www.conjur.com.br/2016-ago-25/senso-incomuminterpretar-art-139-iv-cpc-carta-branca-arbitrio >. Acesso em: 28 ago. 2016.

RODRIGUES, Marcelo Abelha. Manual de Execução Civil. $5^{\text {a }}$ ed. rev. e atual. Rio de Janeiro: Forense, 2015.

Manual de Direito Processual Civil. $5^{\text {a }}$ ed. rev. atual. e ampl. São Paulo: Revista dos Tribunais, 2010.

SIQUEIRA, Cleanto Guimarães. A defesa no processo civil. $3^{\text {a }}$ ed. São Paulo: Saraiva, 2008. 
TARUFFO, Michele. A atuação executiva dos direitos: perfis comparatísticos. São Paulo: Revista de Processo, v. 15, n. 59, p. 72-97, 1990.

TARUFFO, Michele; HAZARD, Geoffrey C. American Civil Procedure: an introduction. New Haven: Yale University press, 1993.

ZANETI JUNIOR, Hermes. A constitucionalização do processo. $2^{\text {a }}$ ed. rev., atual. e ampl. São Paulo: Atlas, 2014. 